ఠ

\title{
Atrial fibrillation in Sub-Saharan Africa: epidemiology, unmet needs, and treatment options
}

This article was published in the following Dove Press journal:

International Journal of General Medicine

31 July 2015

Number of times this article has been viewed

\author{
Bruce Sheldon Stambler' \\ Leonard M Ngunga ${ }^{2}$ \\ 'Department of Cardiac \\ Electrophysiology, Piedmont Heart \\ Institute Cardiology/Electrophysiology, \\ Atlanta, GA, USA; \\ ${ }^{2}$ Department of Cardiology, Aga Khan \\ University Hospital, Nairobi, Kenya
}

Correspondence: Bruce Stambler Department of Cardiac Electrophysiology, Piedmont Heart Institute, 275 Collier Road, Suite 500, Atlanta, GA 30309, USA

Tel +l 4046055536

Fax +I 4043672962

Email bruce.stambler@piedmont.org

\begin{abstract}
Health care in Sub-Saharan Africa is being challenged by a double burden of disease as lifestyle diseases common in the developed world, such as stroke and atrial fibrillation (AF), increase, while, simultaneously, health issues of the developing world in terms of communicable disease persist. The prevalence of AF is lower in Africa than in the developed world but is expected to increase significantly over the next few decades. Patients with AF in Africa tend to be younger and have a higher prevalence of rheumatic valvular heart disease than patients with $\mathrm{AF}$ in other regions. Permanent $\mathrm{AF}$ is the most prevalent type of $\mathrm{AF}$ in Africa, possibly due to the lower use of rhythm control strategies than in the developed world. Mortality rates of patients with $\mathrm{AF}$ in Africa are high, due largely to poor health care access and suboptimal therapy. The risk of stroke in AF, which is moderate to high in Africans as in the developed world, contributes to the high mortality rate. Patients with AF in Africa are often undertreated with antithrombotics, as cost and access to monitoring are major barriers. Vitamin K antagonists, including warfarin, are the most commonly available oral anticoagulants, but regular monitoring can be challenging, especially for patients in remote areas. Several non-vitamin K antagonist oral anticoagulants (NOACs) have been approved for use in countries across Sub-Saharan Africa and have the potential to reduce stroke burden. The higher cost of newer agents may be offset by the reduced need for regular monitoring, fixed dosing, and lower risk of intracranial bleeding; NOACs could provide a treatment option for patients in remote areas with limited access to regular monitoring. However, NOACs are not indicated in valvular AF. More work is needed to increase understanding of the epidemiology of $\mathrm{AF}$ and stroke, as well as to improve management strategies to reduce the burden of cardiovascular disease predicted for Africa.
\end{abstract}

Keywords: stroke, real-world treatment, treatment guidelines, barriers to care, non-vitamin K antagonist oral anticoagulants

\section{Introduction}

Economic and social changes in Sub-Saharan Africa are producing increased prosperity, but unfortunately, they are also driving an epidemiological transition to a double burden of disease in the region. ${ }^{1,2}$ Health care systems in the developing world are challenged both by significant public health issues related to communicable disease and, increasingly, by a rising prevalence of noncommunicable lifestyle diseases, including obesity, tobacco addiction, hypertension, diabetes, and cardiovascular disease. ${ }^{2}$ Atrial fibrillation (AF) is the most common sustained cardiac arrhythmia in the developed world, and its prevalence in Africa is expected to grow as risk factors for AF, including an aging population, increase in this region. ${ }^{3,4}$ Additionally, the large incidence of undertreated streptococcal infections in Africa contributes to the high burden of 
valvular AF associated with rheumatic heart disease. ${ }^{5,6}$ The largest relative increase in cardiovascular disease burden between 1990 and 2010 in Sub-Saharan Africa was in AF. ${ }^{7}$ It is estimated that by 2050 , the prevalence of AF in Africa will be greater than in any other region of the world. ${ }^{8}$

The impact of AF on patients in Africa is not well characterized. However, it is important to increase awareness and understanding of AF in Africa for the future, as AF is a significant risk factor for stroke. Compared with stroke from other causes, a stroke associated with AF tends to be more disabling and carries a higher risk of death. ${ }^{9-11}$ Although the prevalence of stroke in Sub-Saharan Africa remains lower than in many developed countries, the burden of disease is high, with a high incidence of stroke-related mortality. ${ }^{12}$ The leading cardiovascular cause of death and disability in 2010 in Sub-Saharan Africa was stroke. ${ }^{7}$ Even in developed regions where high-quality health care is readily accessible, patients with AF are undertreated with anticoagulant therapy; ${ }^{13,14}$ similarly, data indicate that patients with AF in Africa receive suboptimal antithrombotic treatment to reduce their risk of stroke. ${ }^{2,15}$ Additional attention and resources are needed for prevention and treatment of AF and its associated complications on the African continent and the developing world in general.

\section{Epidemiology}

Data on the prevalence and incidence of AF in Africa are sparse, but several small studies have been published since 2010. A systematic review of AF epidemiology in developing regions suggested that the prevalence of AF in Africa currently is lower than in other regions studied. ${ }^{16}$ The reported prevalence of AF varies somewhat among studies and is expected to differ between hospital-based studies and in the general population, due at least in part to the patient selection in some hospitals being driven by factors such as affordability and health care-seeking behavior. In a hospital-based study in South Africa, 4.6\% of cardiology patients had AF, indicating an estimated prevalence of 5.6 cases per 100,000 population per year. ${ }^{2}$ Similarly, in a retrospective chart review $(\mathrm{N}=3,908)$ at a cardiology institute in Ivory Coast, the prevalence of AF was $5.5 \%$ among patients admitted to the hospital over a 10 -year period. ${ }^{17}$ In a retrospective study at a hospital in Senegal, the overall prevalence of AF was 5.4\% and accounted for $66 \%$ of heart rhythm disorders. ${ }^{18}$ A lower prevalence rate of AF was reported in a Kenyan study in which the prevalence of AF and flutter in a tertiary referral hospital among medical patients was $0.7 \%(162 / 22,144)$; $15 \%$ of these patients presented with a thromboembolic event (of patients with a thromboembolic event, 53\% were of Asian or Caucasian origin). ${ }^{19}$ Among elderly residents ( $\geq 70$ years old) in a rural community in Tanzania, the crude prevalence rate of AF was strikingly low, at $0.7 \% .{ }^{20}$ This estimate is much lower than the AF rates in elderly populations in the US or the European Union, where approximately $5 \%$ of people aged $\geq 65$ years and $10 \%$ of people aged $\geq 80$ years have been diagnosed with AF. ${ }^{21,22}$ The low rate of AF in African populations reported in some studies may be related to health care-seeking behavior and the fact that many patients do not have ready access to good health care. With increased access, it is likely that a higher prevalence of AF will be observed across Sub-Saharan Africa.

With regard to prevalence of AF among the African population, it is notable that the prevalence and incidence of AF in the US is lower among African American men and women than in white men and women, even though risk factors for AF are more common among African Americans. ${ }^{23,24}$ These observations suggest that genetic factors may be contributing to a lower prevalence of AF in native Africans, but at this time, the contribution of genetic variants to a lower AF susceptibility in this population remains uncertain. It will be interesting to study whether environmental factors associated with increased urbanization and life expectancy in some parts of Sub-Saharan Africa will result, as predicted, in a higher AF burden in future years.

AF is independently associated with an increased risk of death. ${ }^{3}$ In the Framingham Heart Study, AF was associated with a 1.5- to 1.9-fold increase in mortality over 40 years of follow-up. ${ }^{25}$ In a study among a predominantly white population in Olmsted County, MN, USA (mean age $73 \pm 14$ years), the Kaplan-Meier estimates of survival at 4 months and 1 year after first AF diagnosis were 83\% (95\% confidence interval [CI]: 82\%-85\%) and 77\% (95\% CI: 76\%-78\%). ${ }^{26}$ Notably, among patients aged $>70$ years with electrocardiogramconfirmed AF in rural Tanzania, the 1-year mortality rate was extremely high $(50.0 \%$ in men and $66.6 \%$ in women $){ }^{20}$ Likewise, among an urban population with AF in Cameroon, the 1-year mortality rate after diagnosis was high $(29.5 \%){ }^{15}$ The lower reported prevalence of AF in Africa may also be related to higher mortality in patients with $\mathrm{AF}$ in that region, due to underdiagnosis and undertreatment in settings with limited health care resources. ${ }^{27}$

The pattern of AF can be classified as paroxysmal, persistent, or permanent. Paroxysmal AF is self-terminating, usually within 48 hours, but may continue for up to 7 days. Persistent AF is present when an AF episode either lasts longer than 7 days or requires termination by cardioversion, either 
with drugs or by direct current cardioversion. Permanent $\mathrm{AF}$ is said to exist when the presence of the arrhythmia is accepted by the patient and physician. Notably, paroxysmal $\mathrm{AF}$ carries the same risk of stroke as permanent or persistent AF. ${ }^{11}$ With regard to these AF subtypes, permanent AF is the most prevalent type of AF among African individuals. In a prospective study of AF patients in Cameroon, the prevalence of paroxysmal, persistent, and permanent AF was $23 \%, 22 \%$, and $56 \%$, respectively. ${ }^{15}$ In a private, urban referral teaching hospital in East Africa, the distribution was paroxysmal AF $40 \%$, persistent AF $13.5 \%$, and permanent AF $40 \%$ (the remainder had incomplete follow-up data). ${ }^{19}$ African patients may progress more rapidly to permanent AF due to the reduced likelihood of detection when AF is paroxysmal and due to the less-frequent use of rhythm control therapies to restore and maintain sinus rhythm. Although some studies suggest that the permanent form of AF may be less common in the US and Europe (estimated prevalence of 30\%-40\%), other studies demonstrate that worldwide, permanent AF occurs in approximately $50 \%$ of patients, and the paroxysmal and persistent forms of AF occur in $25 \%$ each. ${ }^{28-31}$

Patients with AF have a greater risk of stroke than the general population; however, the stroke risk is heterogeneous, modulated significantly by patient comorbidities. A number of risk stratification measures have been developed to predict the risk of stroke among patients with AF. One of the most commonly used and well-validated methods is the $\mathrm{CHADS}_{2}$ score, which stratifies patients by history of Congestive heart failure, Hypertension, Age $\geq 75$ years, Diabetes (one point for each), and Stroke or transient ischemic attack (two points). ${ }^{32}$ Patients with a $\mathrm{CHADS}_{2}$ score of zero are considered to be at lower risk of stroke; those with a score of one are considered to be at moderate risk, while those with a score $\geq 2$ are considered to be at high risk. ${ }^{33,34}$ In a South African hospital-based study, the mean overall $\mathrm{CHADS}_{2}$ score of patients with AF (in 195 nonrheumatic cases) was $1.5 \pm 0.9 .^{2}$ In a study from a cardiac referral center in Cameroon, the mean $\mathrm{CHADS}_{2}$ score was $1.9 \pm 0.1$, and $92 \%$ of patients had a $\mathrm{CHADS}_{2}$ score $\geq 1 .{ }^{15}$ In a study based at the Cardiology Institute in Abidjan, Ivory Coast, $47 \%$ of patients had a $\mathrm{CHADS}_{2}$ score of one or two, while $18 \%$ had a $\mathrm{CHADS}_{2}$ score $\geq 3 .{ }^{17}$ In the Kenya series mentioned previously, $65 \%$ of patients had a $\mathrm{CHADS}_{2}$ score $>2 .{ }^{19}$ Similarly, in a European cohort, $20 \%$ of patients had a $\mathrm{CHADS}_{2}$ score of zero, $62 \%$ had a score of one or two, and $18 \%$ had a score $\geq 3 .{ }^{33}$ Thus, similar to other regions of the world, most patients with $\mathrm{AF}$ in Africa are at moderate-to-high risk of stroke.

The $\mathrm{CHA}_{2} \mathrm{DS}_{2}-\mathrm{VASc}$ point scoring system is a modification of $\mathrm{CHADS}_{2}$, which includes a larger number of risk factors (female sex, 65-74 years of age, and vascular disease) and has a broader score range (zero to nine). $\mathrm{CHA}_{2} \mathrm{DS}_{2}-\mathrm{VASc}$ (rather than $\mathrm{CHADS}_{2}$ ) has been given a Class I recommendation to assess stroke risk according to the 2012 European Society of Cardiology (ESC) and the 2014 American Heart Association/American College of Cardiology/Heart Rhythm Society (AHA/ACC/HRS) AF Guidelines. ${ }^{35,36} \mathrm{CHA}_{2} \mathrm{DS}_{2}$-VASc scores of zero and one are associated with adjusted stroke rates (percentage per year) of $0 \%$ and $1.3 \%$, respectively, and a score of nine has a stroke rate of $15.2 \%{ }^{36}$ Notably in several studies, the $\mathrm{CHA}_{2} \mathrm{DS}_{2}-\mathrm{VASc}$ system discriminated stroke risk better among subjects with a baseline $\mathrm{CHADS}_{2}$ score of zero to one and defined anticoagulation recommendations more clearly than the $\mathrm{CHADS}_{2}$ score. ${ }^{35}$ However, because the $\mathrm{CHA}_{2} \mathrm{DS}_{2}-$ VASc scoring system has not been validated in the native African population, its utility in this setting currently remains uncertain and may be limited pending its validation.

\section{Risk factors for AF Valvular AF}

AF may be divided into two categories: valvular AF and nonvalvular AF (NVAF). Valvular AF can be defined as AF that occurs in association with a prosthetic heart valve, valve repair, or rheumatic valvular heart disease (predominantly mitral stenosis caused by prior streptococcal infection). ${ }^{36}$ Rheumatic heart disease associated with valvular AF is much more common in Africa than in North America or Europe. ${ }^{2}$ Among the regions enrolled in Randomized Evaluation of Long-Term Anticoagulation Therapy (RE-LY) AF, a global prospective registry that enrolled patients presenting to an emergency department with AF, rheumatic heart disease was present in $22 \%$ of African patients vs $2 \%$ of North American patients (Table 1). As a consequence of the higher prevalence

Table I Selected risk factors for AF in African patients compared with the global population enrolled in a prospective registry of emergency department patients presenting with AF

\begin{tabular}{lll}
\hline & Africa & Overall \\
\hline Number of patients with AF & 1,137 & 15,400 \\
Age, years, mean (SD) & $57^{*}(19)$ & $66(15)$ \\
Hypertension, \% & $54^{*}$ & 62 \\
Previous stroke or TIA, \% & 14 & 14 \\
Heart failure, \% & $64^{*}$ & 35 \\
Diabetes mellitus, \% & $14^{*}$ & 22 \\
Rheumatic heart disease, \% & $22^{*}$ & 2 \\
CHADS $_{2}$ score, mean & 1.8 & 1.8 \\
\hline
\end{tabular}

Notes: *Significantly different from the rest of the world $(P<0.005)$. Data from Walker et al. ${ }^{37}$

Abbreviations: AF, atrial fibrillation; $\mathrm{CHADS}_{2}$, Congestive heart failure, Hypertension, Age $\geq 75$ years, and Diabetes (one point each), Stroke or transient ischemic attack (two points); SD, standard deviation; TIA, transient ischemic attack. 
of rheumatic heart disease, AF may affect people in Africa at a younger age than in the US or Europe. In RE-LY AF, Africa had the youngest median age of patients with AF (57.2 years, standard deviation [SD]: 18.8 for African patients vs 70.1 years, SD: 13.4 for North American patients). ${ }^{37}$

\section{NVAF}

Risk factors associated with NVAF include older age, hypertension, diabetes, and heart disease. ${ }^{36}$ Several AF risk factors are prevalent among patients with AF in Africa. In a prospective study of AF patients in Cameroon, underlying cardiac disorders, including hypertensive heart disease (48\%), valvular heart disease (VHD; 26\%), dilated cardiomyopathy (16\%), and coronary artery disease (6\%), were present in 156/172 patients $(91 \%) .{ }^{15}$ Similarly, a retrospective study of patients with AF in a teaching hospital in Kenya reported associated comorbidities, including hypertension (68\%), heart failure (38\%), diabetes mellitus (33\%), and valvular abnormalities $(12 \%) .{ }^{19}$ Among participants in the RE-LY AF registry, some risk factors for AF (older age, hypertension, and diabetes) were lower among Africans than in other regions of the world, but heart failure was much more common in Africans with AF (Table 1).${ }^{37}$ The incidence of NVAF in Africa is likely to increase as rates of hypertension, diabetes, and other risk factors increase and the population ages. ${ }^{2}$

\section{Burden of AF and stroke}

$\mathrm{AF}$ is associated with an increased risk of stroke. Reported stroke prevalence varies throughout Africa, depending on the setting. In a 2007 study, the crude prevalence rate of stroke in urban Nigeria was 1.14/1,000, lower than the rates in most developed countries. ${ }^{38}$ In rural Nigeria, the crude prevalence of stroke was $1.63 / 1,000 .{ }^{39}$ For comparison, the prevalence of stroke among adult African Americans was 3.8\% in 2012. ${ }^{40}$ The lower prevalence in Nigeria may be related to lower incidence and higher stroke mortality compared with developed countries.

Although descriptive data are limited, patients with stroke in Africa are younger and have higher mortality than in other regions. In a single-center study of stroke patients in Ethiopia, the mean age of patients was 53.2 years and overall mortality was $44.5 \%{ }^{41}$ In this study, hypertension was the most frequent risk factor for stroke, followed by cardiac disease, observed in $66 \%$ and $23 \%$ of patients, respectively. Hypertension was undertreated, with most hypertensive patients receiving either no treatment $(29 \%)$ or erratic and irregular treatments $(38 \%)$. In another study from Kenya, the mean age for patients with stroke was 61 years, and hypertension was found in $64 \%{ }^{42}$
Valvular heart disease accounted for $40 \%$ of all heart disease, and almost half the patients with VHD also had AF, of whom none were on treatment.

\section{Treatment options for AF management}

Long-term anticoagulation is recommended to reduce the risk of stroke in patients with AF ${ }^{34,36,43,44}$ The vitamin $\mathrm{K}$ antagonists (VKAs), including warfarin, are well-studied, having been used for many years, and low-cost generic versions are readily available. Warfarin is effective at reducing stroke risk in patients with AF, provided that good anticoagulation control is achieved by maintaining the international normalized ratio (INR) in the therapeutic range for at least $60 \%-70 \%$ of the time. ${ }^{45,46}$ A meta-analysis of six placebo-controlled trials showed that warfarin significantly reduced stroke risk by $64 \%$ and mortality by $26 \% .{ }^{47}$ Use of warfarin, as in the case of all anticoagulants, carries some risk of bleeding. Administration of vitamin $\mathrm{K}$ can substantially reduce the effect of warfarin on INR in 24 hours, but because warfarin has a much longer duration of action than vitamin $\mathrm{K}$, vitamin $\mathrm{K}$ may need to be readministered in patients with ongoing bleeding. ${ }^{48}$ Alternatively, the effect of warfarin can be reversed more rapidly by administering fresh frozen plasma. ${ }^{49}$ Warfarin has a number of other limitations, including its slow onset and offset of action, food and drug interactions that require patients to be consistent in their dietary and alcohol intake, and a narrow therapeutic range that requires regular INR monitoring and dose adjustment to maintain anticoagulant levels within the therapeutic range. ${ }^{50}$

While warfarin remains the most commonly used oral anticoagulant in patients with AF, several non-vitamin $\mathrm{K}$ antagonist oral anticoagulants (NOACs), including dabigatran, rivaroxaban, apixaban, and edoxaban, have recently been approved to reduce the risk of stroke in patients with NVAF. ${ }^{51-54}$ Potential advantages of the NOACs relative to warfarin could be that they do not require routine INR or other anticoagulant level monitoring, they do not have food or drug interactions, and they can be prescribed in fixed doses. Disadvantages of the NOACs compared with warfarin include their cost and the current lack of a specific antidote. Furthermore, they are not indicated for stroke prevention in patients with valvular AF. The efficacy of these agents to reduce the risk of stroke in NVAF has been demonstrated in Phase III trials (Table 2).

In the RE-LY trial, patients with NVAF at moderate-tohigh risk of stroke were randomized to dabigatran (150 mg twice daily [bid] or $110 \mathrm{mg}$ bid) or open-label warfarin. Both doses of dabigatran were noninferior to warfarin at 


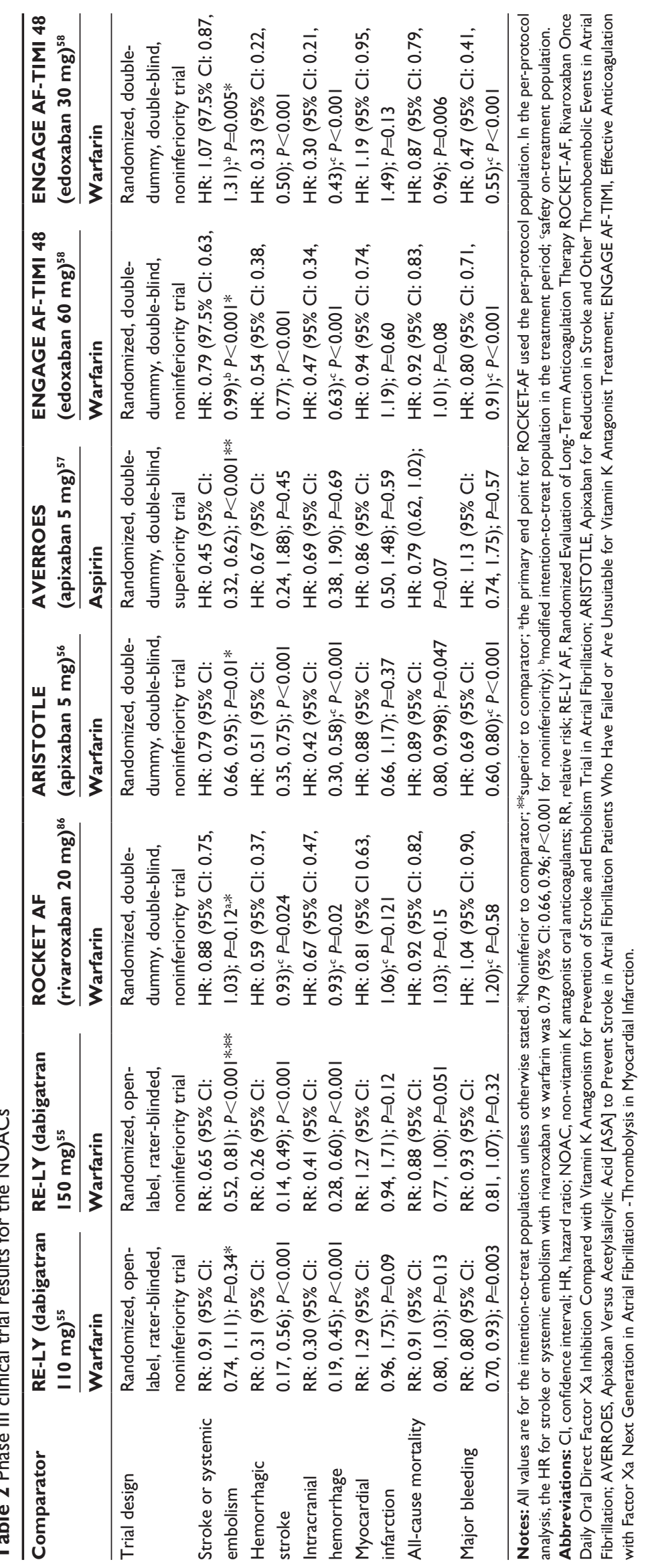


reducing stroke rates. Dabigatran $150 \mathrm{mg}$, but not $110 \mathrm{mg}$, was superior to warfarin. Rates of hemorrhagic stroke were significantly lower in both dabigatran arms than in the warfarin arm. Major bleeding occurred significantly less frequently in the $110 \mathrm{mg}$ dabigatran group and at similar rates in the warfarin and dabigatran $150 \mathrm{mg}$ groups. ${ }^{55}$

In the Rivaroxaban Once Daily Oral Direct Factor Xa Inhibition Compared with Vitamin K Antagonism for Prevention of Stroke and Embolism Trial in Atrial Fibrillation (ROCKET AF) trial, rivaroxaban was noninferior to warfarin for prevention of stroke and systemic embolism in patients with NVAF. There were no significant differences in the rates of major, as well as clinically relevant nonmajor, bleeding in patients taking rivaroxaban and warfarin. Intracranial hemorrhage and fatal bleeding occurred significantly less frequently with rivaroxaban, whereas gastrointestinal bleeding, bleeding that led to a drop in the hemoglobin level, and bleeding that required transfusion occurred more frequently with rivaroxaban.

In the Apixaban for Reduction in Stroke and Other Thromboembolic Events in Atrial Fibrillation (ARISTOTLE) trial, which included patients with NVAF and at least one additional risk factor for stroke, apixaban $5 \mathrm{mg}$ bid ( $2.5 \mathrm{mg}$ bid in selected patients) significantly reduced the risk of stroke or systemic embolism, major bleeding, and mortality compared with warfarin (target INR: 2-3). ${ }^{56}$ In the Apixaban Versus Acetylsalicylic Acid [ASA] to Prevent Stroke in Atrial Fibrillation Patients Who Have Failed or Are Unsuitable for Vitamin K Antagonist Treatment (AVERROES) trial, apixaban $5.0 \mathrm{mg}$ bid $(2.5 \mathrm{mg}$ bid in selected patients) provided significantly more protection from stroke and systemic embolism than aspirin $81-324 \mathrm{mg} /$ day in patients with NVAF at increased risk of stroke, without significantly increasing major bleeding. ${ }^{57}$

In the Effective Anticoagulation with Factor Xa Next Generation in Atrial Fibrillation -Thrombolysis in Myocardial Infarction 48 (ENGAGE AF-TIMI 48) trial, patients with NVAF were randomized to edoxaban $60 \mathrm{mg}$ daily, edoxaban $30 \mathrm{mg}$ daily, or warfarin (target INR: 2-3). Both once-daily regimens of edoxaban were noninferior to warfarin with respect to the prevention of stroke or systemic embolism, as well as being associated with significantly lower rates of bleeding and death from cardiovascular causes. ${ }^{58}$

Notably, a significant limitation of all the NOAC trials with regard to the use of these drugs in the African population is that none of the trials included a large number of patients from Africa, and the percentage of black subjects overall was small. Thus, the use of these newer agents compared with warfarin has not been well validated among subjects from the African continent. Furthermore, the percentage of patients with valvular (rheumatic) AF vs NVAF is expected to be higher in Africa than in some other regions of the world. The NOACs are not indicated in patients with significant VHD (including hemodynamically significant/severe mitral regurgitation or moderate-to-severe mitral or aortic valve stenosis) or in patients with prosthetic heart valves.

As noted earlier, an important drawback of warfarin is that patients require routine monitoring and dose adjustment to maintain serum levels in the therapeutic range. ${ }^{50}$ Access to monitoring may present a significant burden in some regions of Africa due to remote geographic locations or limited resources. Therefore, treatment with NOACs could minimize logistical hurdles for patients who lack access to laboratory services, as these drugs do not require routine monitoring; in the authors' experience, people in remote areas opt to use NOACs instead of warfarin for this reason.

While the NOACs are widely available in Europe and the US, the approval status of these agents varies in the countries of Sub-Saharan Africa. The first NOAC approved for treatment of NVAF in Africa was dabigatran, which received regulatory approval in Namibia in $2011 .{ }^{59}$ As of August 2014, rivaroxaban and dabigatran have been approved in Kenya; ${ }^{60}$ rivaroxaban was the only NOAC approved in South Africa ${ }^{61}$ and Nigeria; ${ }^{62}$ and none of the NOACs were available in Uganda $^{63}$ or Zimbabwe. ${ }^{64}$ Up-to-date information about drug approvals in many countries in the Sub-Saharan region is difficult to obtain, and approvals are continuing; therefore, the list above may be incomplete.

\section{AF stroke prevention treatment guidelines}

Evidence-based guidelines published by national or regional medical associations provide physicians with recommendations on how to manage patients with NVAF (Table 3). The South African Stroke Society guidelines recommend primary stroke prevention for patients with AF stratified by $\mathrm{CHADS}_{2}$ risk score. Under these guidelines, patients with a $\mathrm{CHADS}_{2}$ score of zero may be treated with aspirin; for those with a $\mathrm{CHADS}_{2}$ score of one, warfarin or aspirin may be appropriate; and those with a $\mathrm{CHADS}_{2}$ score of $\geq 2$ should receive warfarin. ${ }^{65}$ In addition to the $\mathrm{CHADS}_{2}$ score, physicians should consider patient preference, bleeding risk, and access to reliable INR monitoring when making treatment decisions.

The ESC guidelines use the $\mathrm{CHA}_{2} \mathrm{DS}_{2}-\mathrm{VASc}$ score to predict stroke risk; the ESC recommends no treatment for 
Table 3 Guideline recommendations on the use of antithrombotic therapy for the prevention of stroke in patients with nonvalvular atrial fibrillation, based on stroke risk

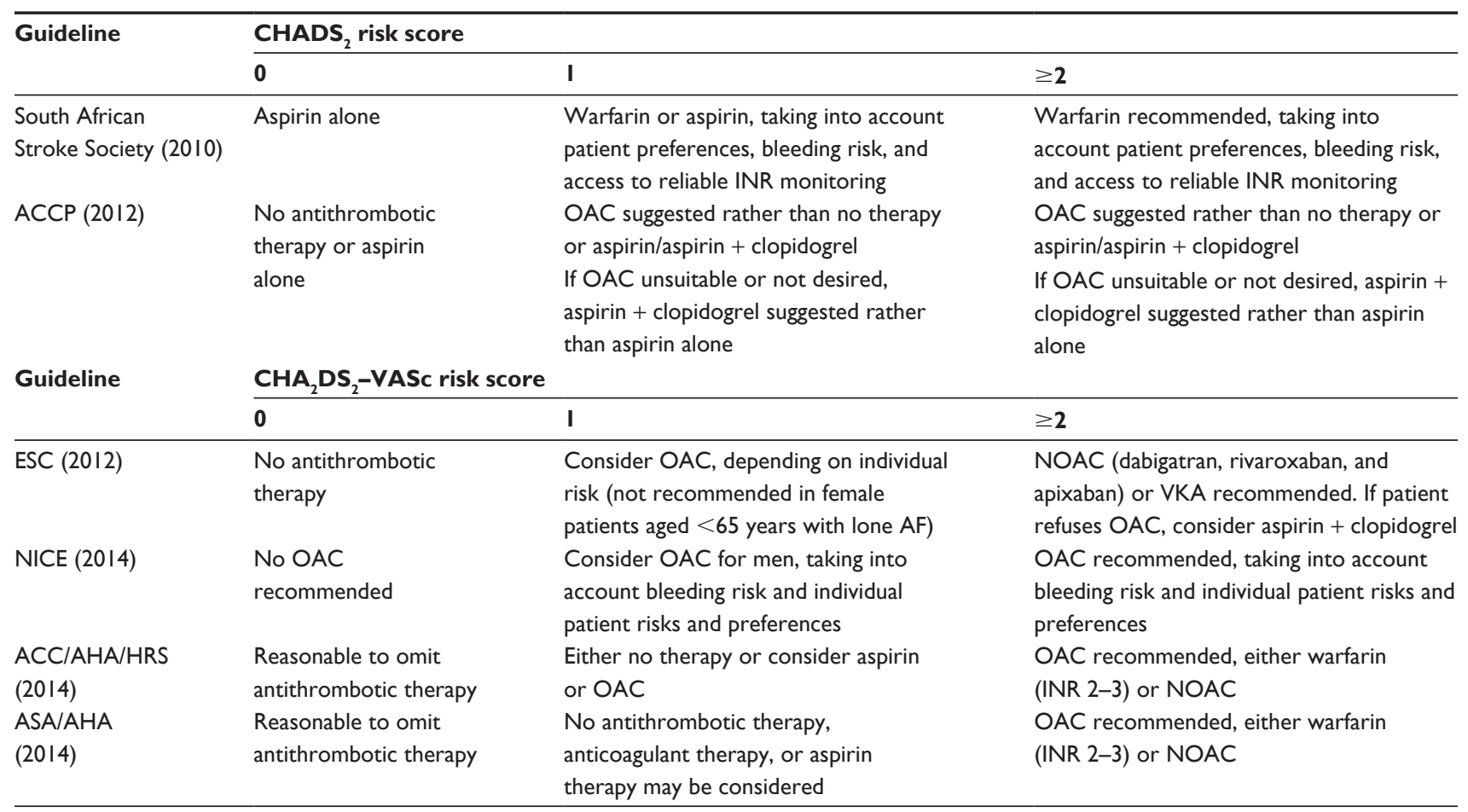

Abbreviations: ACC/AHA/HRS, American College of Cardiology/American Heart Association/Heart Rhythm Society; ACCP, American College of Chest Physicians; AF, atrial fibrillation; ASA, American Stroke Association; $\mathrm{CHADS}_{2}$, Congestive heart failure, Hypertension, Age $\geq 75$ years, Diabetes (one point each), Stroke or transient ischemic attack (two points); ESC, European Society of Cardiology; INR, international normalized ratio; NICE, National Institute for Health and Care Excellence; NOAC, non-vitamin $\mathrm{K}$ antagonist oral anticoagulants; OAC, oral anticoagulant; VKA, vitamin $\mathrm{K}$ antagonist.

patients at low risk $\left(\mathrm{CHA}_{2} \mathrm{DS}_{2}-\mathrm{VASc}\right.$ score of zero) and VKA or NOAC therapy for those at moderate-to-high risk $\left(\mathrm{CHA}_{2} \mathrm{DS}_{2}-\mathrm{VASc}\right.$ score $\left.\geq 1\right)$. In contrast to the South African guidelines, aspirin is recommended only for patients who refuse oral anticoagulant therapy. ${ }^{43}$

The National Institute for Health and Care Excellence (NICE) in the United Kingdom also stratifies patients by the $\mathrm{CHA}_{2} \mathrm{DS}_{2}-$ VASc score. NICE advises that anticoagulation may be established with apixaban, dabigatran, rivaroxaban, or a VKA and recommends considering anticoagulation for men with a $\mathrm{CHA}_{2} \mathrm{DS}_{2}-\mathrm{VASc}$ score of one and offering anticoagulation to men and women with a $\mathrm{CHA}_{2} \mathrm{DS}_{2}-\mathrm{VASc}$ score $\geq 2$. Bleeding risk should be taken into account, and the choice of anticoagulant should be based on the clinical features and preferences of the patient. ${ }^{66}$

In the absence of regional guidelines, physicians in Africa also have the option of referring to any of several different treatment guidelines published by US-based medical societies. The AHA and the American Stroke Association Scientific Advisory use the $\mathrm{CHA}_{2} \mathrm{DS}_{2}$-VASc score and recommend that it is reasonable to omit antithrombotic therapy for patients with a $\mathrm{CHA}_{2} \mathrm{DS}_{2}-\mathrm{VASc}$ score of zero; no antithrombotic therapy, anticoagulant therapy, or aspirin therapy may be considered for patients with a $\mathrm{CHA}_{2} \mathrm{DS}_{2}$-VASc score of one; and oral anticoagulants are recommended for patients with a $\mathrm{CHA}_{2} \mathrm{DS}_{2}-\mathrm{VASc}$ score $\geq 2$. Options include warfarin (INR: 2.0-3.0), dabigatran, apixaban, and rivaroxaban. ${ }^{67}$ The American College of Chest Physicians advises no therapy for patients with a $\mathrm{CHADS}_{2}$ score of zero and oral anticoagulants for patients with $\mathrm{CHADS}_{2}$ score $\geq 1$, with aspirin/ clopidogrel as an alternative for patients for whom oral anticoagulants are not appropriate. ${ }^{44}$ The ACC/AHA/HRS guidelines state that it is reasonable to omit antithrombotic therapy for patients with a $\mathrm{CHA}_{2} \mathrm{DS}_{2}-$ VASc score of zero and suggest an oral anticoagulant or aspirin for patients with a $\mathrm{CHA}_{2} \mathrm{DS}_{2}-\mathrm{VASc}$ score of one. Oral anticoagulants (either warfarin or NOACs) are preferred for patients with $\mathrm{CHA}_{2} \mathrm{DS}_{2}-$ VASc scores $\geq 2 .^{36}$

\section{Costs of AF and stroke}

As in the rest of the world, both the costs associated with AF treatment and the costs of untreated AF are significant concerns in Africa. Indeed, given the paucity of resources available to much of the population of Africa, cost-effective management of AF is of paramount importance. Costs associated with AF may be related to anticoagulant therapy, 
INR monitoring, or treatment of AF-related stroke. Failure to maintain optimal anticoagulation places patients at risk of complications, including both stroke and bleeding, the management of which involves a significant cost. ${ }^{68} \mathrm{~A}$ chart review of stroke patients in Nigeria revealed that patients require an average of US\$600 and $\$ 4,860$ (direct costs only) in a government and a private hospital, respectively, to access care within the first 36 weeks poststroke. ${ }^{69}$ Average income in Nigeria is $<\$ 2 /$ day, which suggests that managing stroke constitutes a huge direct cost burden unaffordable by an average Nigerian stroke sufferer. ${ }^{69}$ Cost-effectiveness studies for the region are limited; however, one study in the South African private sector indicated that compared with warfarin, dabigatran as first-line treatment was cost effective in reducing the risk of stroke in patients with AF when used in accordance with its registered indication. While the costs of dabigatran were estimated to be higher than those for warfarin (Rands [R] 60,365 vs R24,243, respectively), the costs of clinical events and follow-up costs were estimated to be lower than for warfarin (R23,246 vs R24,888 and R236,496 vs R252,229, respectively). ${ }^{70}$

Although NOACs are available in certain parts of Africa, the drug costs of the NOACs make them unaffordable for many patients. Because generic warfarin is available at lower cost, warfarin and other VKAs are likely to remain the standard of care in the region. ${ }^{71}$ Notably, however, as prosperity in Africa (measured as the proportion of the population living above the poverty line) increases, ${ }^{72}$ the African middle class may find the convenience of NOACs, with their reduced burden of monitoring and fewer fooddrug interactions, preferable to warfarin irrespective of their drug-related costs.

\section{Real-world treatment with anticoagulants for stroke prevention}

Several studies have demonstrated wide variability in the use of anticoagulant therapy in clinical practice in Africa, probably related to regional differences in access to medical care across the African continent. In general, treatment patterns differ between rural and urban settings, with urban patients more likely to receive anticoagulants. One study noted that urban patients were more likely to have a relative contraindication to antithrombotic therapy than rural patients $(24 \%$ vs $10 \% ; P=0.028$ ) but received antithrombotic therapy more often $(38 \%$ vs $19 \% ; P=0.025) .{ }^{73}$ In a prospective study of AF patients in Cameroon between 2006 and 2007, in patients with an indication for oral anticoagulation, only 34\% (54 of 158) actually received it. ${ }^{15}$ Similarly, in a hospital-based study from Soweto, South Africa, between 2006 and 2008, $33 \%$ of patients with AF received warfarin. ${ }^{2}$ In contrast, a much higher percentage of patients received an anticoagulant in Senegal, where in a retrospective hospital-based study between 2003 and 2007, anticoagulation by VKA was established in $62 \%$ of cases. ${ }^{18}$ Access to quality health care may be getting better in some parts of Africa with improving economic and social conditions. A study at a private urban referral teaching hospital in Nairobi, Kenya, found that $80 \%$ of patients with $\mathrm{AF}$ and $\mathrm{CHADS}_{2}$ score $\geq 2$ received anticoagulation between 2008 and $2010 .{ }^{19}$ Similarly, a recent observational multicenter national registry in South Africa indicated that $75 \%$ of patients with AF were on warfarin for stroke prevention in 2010 and $2011 .^{74}$

Among patients who receive anticoagulant therapy, INR control varies greatly. In a post hoc analysis of Atrial fibrillation Clopidogrel Trial with Irbesartan for prevention of Vascular Events -Warfarin arm (ACTIVE-W), a randomized prospective trial comparing VKA therapy with clopidogrel plus aspirin, patients from South Africa randomized to VKA therapy $(n=98)$ achieved poor INR control, with the lowest time in therapeutic range (TTR) of any country in the trial. ${ }^{45,75}$ Patients from South Africa had a mean TTR of $46 \%$, vs $63 \%$ for the study population as a whole. ${ }^{45}$ In contrast, in ROCKET-AF, the median individual TTR for South African patients on warfarin was similar to that of the study population as a whole (55\% for each group). ${ }^{76}$ In ARISTOTLE, the median TTR for patients on warfarin was approximately $68 \%$ for patients in South Africa, vs a median of $66 \%(52 \%-77 \%)$ for the study population as a whole. ${ }^{77}$ However, TTR for patients enrolled in randomized controlled clinical trials may not provide an accurate reflection of TTR for patients treated in clinical practice. Among the regions enrolled in the RE-LY AF registry, TTR was lower in Africa than in Europe or North America. ${ }^{37}$ In a multicenter study in South Africa, although all the patients were maintained above the minimum INR value of 2.0, approximately $50 \%$ had at least one record of INR above the cut-off value of 3.5, possibly reflecting barriers of cost and access that may be especially problematic for rural patients. ${ }^{78}$

Observational studies have begun assessing the impact, safety, and efficacy of the NOACs for stroke prevention in AF in routine clinical practice around the world. It will be of interest to understand how these novel treatments are being used in the real-world clinical setting. Global Registry on Long-Term Oral Antithrombotic Treatment in Patients with Atrial Fibrillation (GLORIA-AF) is a large multinational prospective registry designed to characterize the treatment 
of patients newly diagnosed with NVAF who are at risk of stroke and who are being treated with warfarin, aspirin, and NOACs; GLORIA-AF should provide important real-world information on antithrombotic-prescribing patterns and patient outcomes. It is vital to analyze whether the safetyand-efficacy profile of NOACs established in the clinical trials is also observed in routine clinical practice. In this regard, Xarelto ${ }^{\circledR}$ (Janssen Pharmaceuticals, Inc., Titusville, NJ, USA) for Prevention of Stroke in Patients with Nonvalvular Atrial Fibrillation, Eastern Europe, Middle East, Africa, and Latin America (XANTUS-EL) is evaluating rivaroxaban. GLORIA-AF and XANTUS-EL will include South African and Kenyan sites, respectively. Similarly, the ongoing Global Anticoagulant Registry in the FIELD-Atrial Fibrillation (GARFIELD-AF) international observational prospective study aims to investigate real-life treatment patterns and patient outcomes, and it includes South African sites. ${ }^{79,80}$

\section{Rate control vs rhythm control in AF}

Although stroke prevention is a critically important therapeutic goal in AF patients, management of AF patients is also aimed at reducing symptoms and preventing other complications associated with AF by control of the ventricular rate and correction of the rhythm disturbance. Rate control appears to be the preferred treatment strategy relative to rhythm control for AF management among most clinicians treating patients with AF in Africa. At a private referral hospital in Nairobi, rate control, using a mixture of digoxin, betablockers, calcium channel blockers, and amiodarone, alone and in combination, was the preferred strategy for arrhythmia management in $78 \%$ of patients. ${ }^{19}$ A national observational registry in South Africa found that rate control, mainly with beta-blockers, was pursued in $64 \%$ of AF patients. ${ }^{74}$ A prospective study involving ten cardiologists in Cameroon treating AF found that a rate control strategy using digoxin and amiodarone was chosen in $84 \%$ of patients. ${ }^{15}$ Consistent with these observations, a study that assessed pharmacological management of AF in developing countries around the world found a high prevalence of rate control therapy use $(55 \%-87 \%){ }^{16}$ This treatment approach contrasts with AF management in developed countries, where physicians generally prefer rhythm control over rate control strategies. The REgistry on Cardiac rhythm disORDers assessing the control of Atrial Fibrillation (RecordAF) observational study of AF management among recently diagnosed patients in Europe, America, and Asia reported that rhythm control was applied to $55 \%$ of patients, whereas rate control was selected in $45 \%$ of patients at baseline. ${ }^{81}$ Similarly, in the Euro Heart Survey,
$67 \%$ of symptomatic patients with AF were managed with a rhythm control approach. ${ }^{28}$

\section{Barriers to evidence-based health care in patients with AF}

While the provision of good health care at low cost is an extremely complex undertaking, countries such as Ethiopia have substantially improved their health care systems in recent years, and their success points to factors that may affect the ability of other countries to improve. ${ }^{82}$ Factors that influenced success included political commitment, effective bureaucracies, and the ability to innovate and adapt to resource limitations. ${ }^{82}$

In Sub-Saharan Africa, the leading cardiovascular cause of death and disability is stroke, and cardiovascular deaths occur at younger ages than in the rest of the world. ${ }^{7}$ Rates of stroke-related disability and mortality are ten fold higher in medically underserved regions of the world compared with the most developed nations. ${ }^{83}$ This is primarily due to the lack of access to primary care to screen for and mitigate stroke risk factors. ${ }^{83}$ In the developed world, AF is the leading preventable cause of stroke, accounting for $15 \%-20 \%$ of all strokes. ${ }^{84}$ Therefore, effective strategies to reduce the risk of stroke in patients with AF must be considered in the context of local health care systems.

A recent proof-of-concept study in Ethiopia and Swaziland adapted tools and systems originally developed for long-term routine care of patients with HIV to treat patients with noncommunicable diseases using diabetes mellitus, another condition requiring ongoing monitoring and care, as a test case. ${ }^{85}$ The study demonstrated the potential to rapidly improve the quality of care for diabetes by adapting HIV-specific policies, systems, and tools. ${ }^{85}$ This approach could potentially be expanded to other noncommunicable conditions, such as AF.

\section{Summary and conclusion}

Although infectious disease has historically been a greater health concern in Africa, noncommunicable disease, including $\mathrm{AF}$ and stroke, is a growing issue in a setting where resources and access to health care are extremely limited for a large portion of the population. Data on epidemiology of AF in Africa are scarce. The available information suggests a lower prevalence of diagnosed AF currently in Sub-Saharan Africa, but the prevalence of $\mathrm{AF}$ in this region is expected to grow significantly over the next 2-3 decades. When AF is detected in Africa, it is more likely to be permanent and associated with high morbidity and mortality. Patients with AF in Africa are 
much more likely to be treated with rate control rather than rhythm control in comparison with patients in Europe or the US. Valvular AF is much more common in Africa than in Europe or the US due to the high burden of rheumatic heart disease. Warfarin or the NOACs are treatment options for stroke prevention in NVAF, whereas the NOACs are not indicated for treatment of valvular AF. While undertreatment of AF remains a worldwide problem, patients with AF in Africa are even more likely to be undertreated than those in other regions due to major differences in the availability of health care resources and socioeconomic conditions. In most of Africa, fewer patients with AF receive anticoagulant therapy compared with those in other parts of the world. In addition, some studies suggest that those receiving treatment may have shorter times in the therapeutic range while receiving warfarin. Although the overall prevalence of stroke in Africa is low compared with that in the developed world, possibly due to the younger age of the region's population, AF is a leading preventable cause of stroke. Undertreatment of AF patients with antithrombotic therapy leaves patients at increased risk of stroke. Furthermore, morbidity and mortality associated with AF-related stroke is significant. NOACs are starting to become available around Africa, and as availability increases, health care providers in Africa will have new treatment options to manage NVAF and reduce the risk of stroke in their patients. More studies and resources are needed to improve understanding of the epidemiology and management of AF in Sub-Saharan Africa.

\section{Acknowledgments}

Professional medical writing and editorial assistance were provided by Nicole Draghi and Rosemary Perkins at Caudex Medical and were funded by Bristol-Myers Squibb Company and Pfizer Inc.

\section{Disclosure}

Dr Stambler has served on speakers bureaus for Pfizer Inc., Bristol-Meyers Squibb Company, Boehringer Ingelheim, and Janssen Pharmaceuticals. He has also consulted for Janssen Pharmaceuticals and has received financial support for publications from Pfizer Inc. and Bristol-Meyers Squibb Company. Dr Ngunga reports no conflicts of interest in this work.

\section{References}

1. World Bank. Disease Control Priorities in Developing Countries. 2nd ed. Washington, DC: World Bank; 2006.

2. Sliwa K, Carrington MJ, Klug E, et al. Predisposing factors and incidence of newly diagnosed atrial fibrillation in an urban African community: insights from the Heart of Soweto Study. Heart. 2010;96(23): 1878-1882.
3. Fuster V, Rydén LE, Cannom DS, et al; American College of Cardiology Foundation/American Heart Association Task Force. 2011 ACCF/ AHA/HRS focused updates incorporated into the ACC/AHA/ESC 2006 guidelines for the management of patients with atrial fibrillation: a report of the American College of Cardiology Foundation/American Heart Association Task Force on practice guidelines. Circulation. 2011; 123(10):e269-e367.

4. United Nations, Department of Economic and Social Affairs Population Division 2013. World Population Prospects: The 2012 Revision. Special Aggregates - DVD-ROM Edition - Dataset in Excel Format (United Nations Publication ST/ESA/SER.A/335); 2014. Available from: http://esa.un.org/unpd/wpp/SpecialAggregates/ DISK_NAVIGATION_EXCEL_Geographical.htm. Accessed September 2, 2014.

5. Bloomfield GS, Barasa FA, Doll JA, Velazquez EJ. Heart failure in sub-Saharan Africa. Curr Cardiol Rev. 2013;9(2):157-173.

6. Damasceno A, Mayosi BM, Sani M, et al. The causes, treatment, and outcome of acute heart failure in 1006 Africans from 9 countries. Arch Intern Med. 2012;172(18):1386-1394.

7. Moran A, Forouzanfar M, Sampson U, Chugh S, Feigin V, Mensah G. The epidemiology of cardiovascular diseases in sub-Saharan Africa: the global burden of diseases, injuries and risk factors 2010 study. Prog Cardiovasc Dis. 2013;56(3):234-239.

8. Rahman F, Kwan GF, Benjamin EJ. Global epidemiology of atrial fibrillation. Nat Rev Cardiol. 2014;11(11):639-654.

9. Hannon N, Sheehan O, Kelly L, et al. Stroke associated with atrial fibrillation - incidence and early outcomes in the north Dublin population stroke study. Cerebrovasc Dis. 2010;29(1):43-49.

10. Lin HJ, Wolf PA, Kelly-Hayes M, et al. Stroke severity in atrial fibrillation. The Framingham Study. Stroke. 1996;27(10):1760-1764.

11. Camm AJ, Kirchhof P, Lip GY, et al. Guidelines for the management of atrial fibrillation: the Task Force for the Management of Atrial Fibrillation of the European Society of Cardiology (ESC). Eur Heart J. 2010; 31(19):2369-2429.

12. Feigin VL, Forouzanfar MH, Krishnamurthi R, et al; Global Burden of Diseases, Injuries, and Risk Factors Study 2010 (GBD 2010) and the GBD Stroke Experts Group. Global and regional burden of stroke during 1990-2010: findings from the Global Burden of Disease Study 2010. Lancet. 2014;383(9913):245-254.

13. Anderson N, Fuller R, Dudley N. 'Rules of thumb' or reflective practice? Understanding senior physicians' decision-making about antithrombotic usage in atrial fibrillation. QJM. 2007;100(5):263-269.

14. Baker WL, Cios DA, Sander SD, Coleman CI. Meta-analysis to assess the quality of warfarin control in atrial fibrillation patients in the United States. J Manag Care Pharm. 2009;15(3):244-252.

15. Ntep-Gweth M, Zimmermann M, Meiltz A, et al. Atrial fibrillation in Africa: clinical characteristics, prognosis, and adherence to guidelines in Cameroon. Europace. 2010;12(4):482-487.

16. Nguyen TN, Hilmer SN, Cumming RG. Review of epidemiology and management of atrial fibrillation in developing countries. Int J Cardiol. 2013;167(6):2412-2420.

17. Coulibaly I, Anzouan-Kacou JB, Konin KC, Kouadio SC, Abouo-N'Dori R. Fibrillation auriculaire: epidémiologie i l'institut de cardiologie d'Abidjan (Côte d'Lvoire) [Atrial fibrillation: epidemiological data from the Cardiology Institute in Abidjan, Cote d'Ivoire]. Med Trop (Mars). 2010;70(4): 371-374.

18. Mbaye A, Pessinaba S, Bodian M, et al. La fibrillation atriale, fréquence, facteurs étiologiques, évolution et traitement dans un service de cardiologie de Dakar, Sénégal [Atrial fibrillation, frequency, etiologic factors, evolution and treatment in a cardiology department in Dakar, Senegal]. Pan Afr Med J. 2010;6:16.

19. Shavadia J, Yonga G, Mwanzi S, Jinah A, Moriasi A, Otieno H. Clinical characteristics and outcomes of atrial fibrillation and flutter at the Aga Khan University Hospital, Nairobi. Cardiovasc J Afr. 2013; 24(2):6-9.

20. Dewhurst MJ, Adams PC, Gray WK, et al. Strikingly low prevalence of atrial fibrillation in elderly Tanzanians. J Am Geriatr Soc. 2012;60(6): 1135-1140. 
21. Miyasaka Y, Barnes ME, Gersh BJ, et al. Secular trends in incidence of atrial fibrillation in Olmsted County, Minnesota, 1980 to 2000, and implications on the projections for future prevalence. Circulation. 2006;114(2):119-125.

22. Lloyd-Jones D, Adams RJ, Brown TM, et al; American Heart Association Statistics Committee and Stroke Statistics Subcommittee. Heart disease and stroke statistics - 2010 update: a report from the American Heart Association. Circulation. 2010;121(7):e46-e215.

23. Alonso A, Agarwal SK, Soliman EZ, et al. Incidence of atrial fibrillation in whites and African-Americans: the atherosclerosis risk in communities (ARIC) study. Am Heart J. 2009;158(1):111-117.

24. Huxley RR, Lopez FL, Folsom AR, et al. Absolute and attributable risks of atrial fibrillation in relation to optimal and borderline risk factors: the atherosclerosis risk in communities (ARIC) study. Circulation. 2011; 123(14):1501-1508.

25. Benjamin EJ, Wolf PA, D’Agostino RB, Silbershatz H, Kannel WB, Levy D. Impact of atrial fibrillation on the risk of death: the Framingham Heart Study. Circulation. 1998;98(10):946-952.

26. Miyasaka Y, Barnes ME, Bailey KR, et al. Mortality trends in patients diagnosed with first atrial fibrillation: a 21-year community-based study. J Am Coll Cardiol. 2007;49(9):986-992.

27. Walker RW, Dewhurst M, Gray WK, et al. Electrocardiographic assessment of coronary artery disease and stroke risk factors in rural and urban Tanzania: a case-control study. J Stroke Cerebrovasc Dis. 2014;23(2):315-320.

28. Nieuwlaat R, Capucci A, Camm AJ, et al; European Heart Survey Investigators. Atrial fibrillation management: a prospective survey in ESC member countries: the Euro Heart Survey on atrial fibrillation. Eur Heart J. 2005;26(22):2422-2434.

29. Kirchhof P, Ammentorp B, Darius H, et al. Management of atrial fibrillation in seven European countries after the publication of the 2010 ESC Guidelines on atrial fibrillation: primary results of the PREvention oF thromboemolic events - European Registry in Atrial Fibrillation (PREFER in AF). Europace. 2014;16(1):6-14.

30. Chiang CE, Naditch-Brûlé L, Murin J, et al. Distribution and risk profile of paroxysmal, persistent, and permanent atrial fibrillation in routine clinical practice: insight from the real-life global survey evaluating patients with atrial fibrillation international registry. Circ Arrhythm Electrophysiol. 2012;5(4):632-639.

31. Zoni-Berisso M, Lercari F, Carazza T, Domenicucci S. Epidemiology of atrial fibrillation: European perspective. Clin Epidemiol. 2014;6: 213-220.

32. Gage BF, Waterman AD, Shannon W, Boechler M, Rich MW, Radford MJ. Validation of clinical classification schemes for predicting stroke: results from the National Registry of Atrial Fibrillation. JAMA 2001;285(22):2864-2870.

33. Lip GY, Nieuwlaat R, Pisters R, Lane DA, Crijns HJ. Refining clinical risk stratification for predicting stroke and thromboembolism in atrial fibrillation using a novel risk factor-based approach: the Euro Heart Survey on atrial fibrillation. Chest. 2010;137(2):263-272.

34. Furie KL, Goldstein LB, Albers GW, et al; American Heart Association Stroke Council; Council on Quality of Care and Outcomes Research; Council on Cardiovascular Nursing; Council on Clinical Cardiology; Council on Peripheral Vascular Disease. Oral antithrombotic agents for the prevention of stroke in nonvalvular atrial fibrillation: a science advisory for healthcare professionals from the American Heart Association/American Stroke Association. Stroke. 2012;43(12):3442-3453.

35. Camm AJ, Lip GY, De Caterina R, et al; ESC Committee for Practice Guidelines (CPG). 2012 Focused update of the ESC Guidelines for the management of atrial fibrillation: An update of the 2010 ESC Guidelines for the management of atrial fibrillation. Developed with the special contribution of the European Heart Rhythm Association. Eur Heart J. 2012;33(21):2719-2747.

36. January CT, Wann LS, Alpert JS, et al; ACC/AHA Task Force Members. 2014 AHA/ACC/HRS Guideline for the management of patients with atrial fibrillation: executive summary: a report of the American College of Cardiology/American Heart Association Task Force on practice guidelines and the Heart Rhythm Society. J Am Coll Cardiol. 2014;64(21):e1-e76.
37. Oldgren J, Healey JS, Ezekowitz M, et al; RE-LY Atrial Fibrillation Registry Investigators. Variations in cause and management of atrial fibrillation in a prospective registry of 15400 emergency department patients in 46 countries: the RE-LY Atrial Fibrillation Registry. Circulation. 2014;129(15):1568-1576.

38. Danesi M, Okubadejo N, Ojini F. Prevalence of stroke in an urban, mixed-income community in Lagos, Nigeria. Neuroepidemiology. 2007; 28(4):216-223.

39. Enwereji KO, Nwosu MC, Ogunniyi A, Nwani PO, Asomugha AL, Enwereji EE. Epidemiology of stroke in a rural community in Southeastern Nigeria. Vasc Health Risk Manag. 2014;10:375-388.

40. Go AS, Mozaffarian D, Roger VL, et al; American Heart Association Statistics Committee and Stroke Statistics Subcommittee. Heart disease and stroke statistics - 2014 update: a report from the American Heart Association. Circulation. 2014;129(3):e28-e292.

41. Zenebe G, Alemayehu M, Asmera J. Characteristics and outcomes of stroke at Tikur Anbessa Teaching Hospital, Ethiopia. Ethiop Med J. 2005;43(4):251-259.

42. Jowi JO, Mativo PM. Pathological sub-types, risk factors and outcome of stroke at the Nairobi Hospital, Kenya. East Afr Med J. 2008;85(12): $572-581$.

43. Camm AJ, Lip GY, De Caterina R, et al; ESC Committee for Practice Guidelines-CPG; Document Reviewers. 2012 Focused update of the ESC Guidelines for the management of atrial fibrillation: an update of the 2010 ESC guidelines for the management of atrial fibrillation developed with the special contribution of the European Heart Rhythm Association. Europace. 2012;14(10):1385-1413.

44. You JJ, Singer DE, Howard PA, et al; American College of Chest Physicians. Antithrombotic therapy for atrial fibrillation: Antithrombotic Therapy and Prevention of Thrombosis, 9th ed: American College of Chest Physicians evidence-based clinical practice guidelines. Chest. 2012;141(2 Suppl):e531S-e575S.

45. Connolly SJ, Pogue J, Eikelboom J, et al; ACTIVE W Investigators. Benefit of oral anticoagulant over antiplatelet therapy in atrial fibrillation depends on the quality of international normalized ratio control achieved by centers and countries as measured by time in therapeutic range. Circulation. 2008;118(20):2029-2037.

46. Morgan CL, McEwan P, Tukiendorf A, Robinson PA, Clemens A, Plumb JM. Warfarin treatment in patients with atrial fibrillation: observing outcomes associated with varying levels of INR control. Thromb Res. 2009; 124(1):37-41.

47. Hart RG, Pearce LA, Aguilar MI. Meta-analysis: antithrombotic therapy to prevent stroke in patients who have nonvalvular atrial fibrillation. Ann Intern Med. 2007;146(12):857-867.

48. DeZee KJ, Shimeall WT, Douglas KM, Shumway NM, O’Malley PG. Treatment of excessive anticoagulation with phytonadione (vitamin K): a meta-analysis. Arch Intern Med. 2006;166(4):391-397.

49. Hanley JP. Warfarin reversal. J Clin Pathol. 2004;57(11):1132-1139.

50. Bristol-Myers Squibb. Coumadin Prescribing Information; 2011. Available from: http://packageinserts.bms.com/pi/pi_coumadin.pdf. Accessed October 11, 2013.

51. Boehringer Ingelheim. Pradaxa ${ }^{\circledR}$ (Dabigatran Etexilate Capsules) Prescribing Information: 2014. Available from: http://www.accessdata. fda.gov/drugsatfda_docs/label/2013/022512s017lbl.pdf. Accessed September 18, 2013.

52. Janssen Pharmaceuticals, Inc. Xarelto ${ }^{\circledR}$ (Rivaroxaban Tablets) Prescribing Information; 2014. Available from: http://www.xareltohcp. com/sites/default/files/pdf/xarelto_0.pdf\#zoom=100. Accessed March 8, 2014.

53. Bristol-Myers Squibb. Eliquis ${ }^{\circledR}$ (Apixaban Tablets) Prescribing Information; 2014. Available from: http://packageinserts.bms.com/pi/pi_eliquis. pdf. Accessed March 20, 2014.

54. Food and Drug Administration. FDA Approves Anticlotting Drug Savaysa; 2015. Available from: http://www.fda.gov/NewsEvents/Newsroom/ PressAnnouncements/ucm429523.htm. Accessed January 8, 2015.

55. Connolly SJ, Ezekowitz MD, Yusuf S, et al; RE-LY Steering Committee and Investigators. Dabigatran versus warfarin in patients with atrial fibrillation. N Engl J Med. 2009;361(12):1139-1151. 
56. Granger CB, Alexander JH, McMurray JJ, et al; ARISTOTLE Committees and Investigators. Apixaban versus warfarin in patients with atrial fibrillation. $N$ Engl J Med. 2011;365(11):981-992.

57. Connolly SJ, Eikelboom J, Joyner C, et al; AVERROES Steering Committee and Investigators. Apixaban in patients with atrial fibrillation. N Engl J Med. 2011;364(9):806-817.

58. Giugliano RP, Ruff CT, Braunwald E, et al; ENGAGE AF-TIMI 48 Investigators. Edoxaban versus warfarin in patients with atrial fibrillation. N Engl J Med. 2013;369(22):2093-2104.

59. Wagenaar P. Namibia becomes first country in Africa to launch dabigatran etexilate for atrial fibrillation. Cardiovasc J Afr. 2011; 22(5):283.

60. Kenya Pharmacy and Poisons Board. Registered Human Drugs; 2014. Available from: http://pharmacyboardkenya.org/?p=513. Accessed August 24, 2014.

61. Bayer's Xarelto is approved in South Africa across five additional indications. Cardiovasc J Afr. 2014;25(2):90-92.

62. Nigeria National Agency for Food and Drug Administration and Control. Drugs; 2015. Available from: http://www.nafdac.gov.ng/index. $\mathrm{php} /$ product-registration/registered-drugs?resetfilters $=0$. Accessed February 20, 2015.

63. Uganda National Drug Authority. Drug Register; 2014. Available from: http://www.nda.or.ug/hmn_list.php. Accessed August 25, 2014.

64. Medicines Control Authority of Zimbabwe. Medicines Registers; 2014. Available from: http://www.mcaz.co.zw/index.php/downloads/ category/17-registers. Accessed August 25, 2014.

65. Bryer A, Connor M, Haug P, et al. South African guideline for management of ischaemic stroke and transient ischaemic attack 2010: a guideline from the South African Stroke Society (SASS) and the SASS Writing Committee. S Afr Med J. 2010;100(11 pt 2):747-778.

66. National Institute for Health and Clinical Excellence. Atrial Fibrillation: The Management of Atrial Fibrillation [cg180]; 2014. Available from: guidance.nice.org.uk/cg180. Accessed September 2, 2014.

67. Meschia JF, Bushnell C, Boden-Albala B, et al; American Heart Association Stroke Council; Council on Cardiovascular and Stroke Nursing; Council on Clinical Cardiology; Council on Functional Genomics and Translational Biology; Council on Hypertension. Guidelines for the primary prevention of stroke: a statement for healthcare professionals from the American Heart Association/American Stroke Association. Stroke. 2014;45(12):3754-3832.

68. Szucs TD, Bramkamp M. Pharmacoeconomics of anticoagulation therapy for stroke prevention in atrial fibrillation: a review. J Thromb Haemost. 2006;4(6):1180-1185.

69. Birabi BN, Oke KI, Dienye PO, Okafor UC. Cost burden of post stroke condition in Nigeria: a pilot study. Glob J Health Sci. 2012;4(6): $17-22$.

70. Bergh M, Marais CA, Miller-Janson H, Salie F, Stander MP. Economic appraisal of dabigatran as first-line therapy for stroke prevention in atrial fibrillation. SAfr Med J. 2013;103(4):241-245.

71. Dalby AJ, Wessels P, Opie LH. Warfarin in non-valvular atrial fibrillation. S Afr Med J. 2013;103(12):901-904.
72. World Bank. Poverty and Equity Regional Dashboard for Sub-Saharan Africa; 2014. Available from: http://povertydata.worldbank.org/poverty/ region/SSA. Accessed September 2, 2014.

73. Bhagat K, Tisocki K. Prescribing patterns for the use of antithrombotics in the management of atrial fibrillation in Zimbabwe. Cent Afr J Med. 1999;45(11):287-290.

74. Jardine RM, Fine J, Obel IW. A survey on the treatment of atrial fibrillation in South Africa. S Afr Med J. 2014;104(9):623-627.

75. Aalbers J. South Africa's poor warfarin control raises questions of benefit above other anticoagulant therapies in atrial fibrillation. Cardiovasc J Afr. 2011;22(4):220.

76. Singer DE, Hellkamp AS, Piccini JP, et al; ROCKET AF Investigators. Impact of global geographic region on time in therapeutic range on warfarin anticoagulant therapy: data from the ROCKET AF clinical trial. J Am Heart Assoc. 2013;2(1):e00067.

77. Wallentin L, Lopes RD, Hanna M, et al; Apixaban for Reduction in Stroke and Other Thromboembolic Events in Atrial Fibrillation (ARISTOTLE) Investigators. Efficacy and safety of apixaban compared with warfarin at different levels of predicted international normalized ratio control for stroke prevention in atrial fibrillation. Circulation. 2013;127(22):2166-2176.

78. Njovane XW, Fasinu PS, Rosenkranz B. Comparative evaluation of warfarin utilisation in two primary healthcare clinics in the Cape Town area. Cardiovasc J Afr. 2013;24(2):19-23.

79. Kakkar AK, Mueller I, Bassand JP, et al. International longitudinal registry of patients with atrial fibrillation at risk of stroke: Global Anticoagulant Registry in the FIELD (GARFIELD). Am Heart J. 2012; 163(1):13-19.

80. Thrombosis Research Institute London. GARFIELD-AF Status; 2014. Available from: http://www.tri-london.ac.uk/garfield/status. Accessed November 17, 2014.

81. Camm AJ, Breithardt G, Crijns H, et al. Real-life observations of clinical outcomes with rhythm- and rate-control therapies for atrial fibrillation RECORDAF (Registry on Cardiac Rhythm Disorders Assessing the Control of Atrial Fibrillation). J Am Coll Cardiol. 2011;58(5): 493-501.

82. Balabanova D, Mills A, Conteh L, et al. Good health at low cost 25 years on: lessons for the future of health systems strengthening. Lancet. 2013; 381(9883):2118-2133.

83. Norrving B, Kissela B. The global burden of stroke and need for a continuum of care. Neurology. 2013;80(3 Suppl 2):S5-S12.

84. Singer DE, Albers GW, Dalen JE, et al; American College of Chest Physicians. Antithrombotic therapy in atrial fibrillation: American College of Chest Physicians Evidence-Based Clinical Practice Guidelines (8th Edition). Chest. 2008;133(6 Suppl):546S-592S.

85. Rabkin M, Melaku Z, Bruce K, et al. Strengthening health systems for chronic care: leveraging HIV programs to support diabetes services in Ethiopia and Swaziland. J Trop Med. 2012;2012:137460.

86. Patel MR, Mahaffey KW, Garg J, et al; ROCKET AF Investigators. Rivaroxaban versus warfarin in nonvalvular atrial fibrillation. $N$ Engl J Med. 2011;365(10):883-891.
International Journal of General Medicine

\section{Publish your work in this journal}

The International Journal of General Medicine is an international, peer-reviewed open-access journal that focuses on general and internal medicine, pathogenesis, epidemiology, diagnosis, monitoring and treatment protocols. The journal is characterized by the rapid reporting of reviews, original research and clinical studies across all disease areas.
Dovepress

A key focus is the elucidation of disease processes and management protocols resulting in improved outcomes for the patient. The manuscript management system is completely online and includes a very quick and fair peer-review system. Visit http://www.dovepress.com testimonials.php to read real quotes from published authors. 